\title{
O engajamento político e historiográfico no ofício dos historiadores brasileiros: uma reflexāo sobre a fundaçāo da historiografia brasileira contemporânea (1975-1979)
}

\author{
The political and historiographic engagement in the profession of \\ Brazilian historians: a reflection on the foundation of contemporary \\ Brazilian historiography (1975-1979)
}

\section{Rodrigo Perez Oliveira}

\section{RESUMO}

Tomando como recorte de análise os anos de vigência do I Plano Nacional de Pós-Graduação (1975-1979), este artigo examina a institucionalização do tipo de historiografia que até hoje é chancelada como profissional. A hipótese apresentada sugere que nesse período havia uma forte tendência de engajamento dos intelectuais nas agendas abertas pela redemocratização. Esse clima geral de engajamento levou os historiadores a tematizarem aquilo que já na época ficou conhecido como "novo sindicalismo", o que trouxe os trabalhadores rurais e urbanos para o primeiro plano dos interesses da historiografia acadêmica. A inflexão empírica característica dos ventos teóricos neohistoricistas que sopravam à época inspirou os historiadores a produzirem, prioritariamente, estudos de caso com objetos rigidamente recortados. A institucionalização acadêmica dessa inflexão empírica interditou o estilo ensaístico, o exercício da síntese e a diacronia de média e longa duração, dificultando a afirmação no debate público da história como uma ciência social aplicada, o que explica a quase total ausência dos historiadores nas instituições que estavam mediando o ativismo político direto dos intelectuais. O principal aspecto da reflexão desenvolvida neste artigo é a tensão complementar entre um intenso engajamento historiográfico e um tímido engajamento político direto no ofício dos historiadores brasileiros durante os primeiros anos da redemocratização no país.

\section{PALAVRAS-CHAVE}

Ditadura militar; Historiografia; Historiadores

\section{ABSTRACT}

Taking the years of validity of I Plano Nacional de PósGraduação (1975-1979), this article analyzes the institutionalization of the type of historiography that until today is defined as professional. The assumption presented suggests that in this period there were a strong trend of engagement of intellectuals in the themes opened up by the re-democratization. This climate general of engagement prompted historians to study what at the time was called "new syndicalism", which introduced rural and urban workers in the foreground of the interests of academic historiography. The empirical change-over which was the characteristic of neohistoricists theoretical debates that marked the epoch inspired the historians to make case studies characterized by objects rigidly delimited. The academic institutionalization of this change-over interdicted the essay style, the practice of synthesis and the exercise of medium and long duration diachrony. This situation made it difficult the affirmation of History in the public debate as an applied social science. This explains the almost total absence of historians in the institutions that in the late 1970s intermediated directly the political activism of intellectuals. The main feature of the reflection developed in this article is the complementary tension between an intense historiographic engagement and a shy direct political engagement in in the office of Brazilian historians during the first years of redemocratization.

\section{KEYWORDS}

Military dictatorship; Historiography; Historians 
Hoje mais do que nunca, há pessoas querendo coisas. No rastro desses centros ausentes e metanarrativas ruídas, as condições do pós-modernismo produzem aquela multiplicidade de relatos históricos que encontramos por toda a parte em nossas sociedades democráticas/consumistas, uma massa de gêneros (histórias com grife) para usar e/ou abusar a gosto. Nisso podemos identificar, por exemplo, as histórias dos historiadores (histórias profissionais que tentam estabelecer hegemonia naquele campo de estudo, uma versão expressa nas teses, monografias, artigos e livros), as histórias dos professores de escola (necessariamente popularizações das histórias dos historiadores profissionais) e depois toda uma gama de outras formas características que só podemos listar: relatos históricos para crianças, relatos da memória popular, relatos de negros, brancos, mulheres, feministas, homens, relatos de herança cultural, relatos de reacionários, elites marginais, etc (JENKINS 2007, p. 101).

Naqueles anos [década de 1970] todos nós estávamos interessados no desenvolvimento de uma pesquisa engajada, amalgamada a atividades de assessoria aos trabalhadores. Pesquisa esta que incluía, a princípio, a participação ativa desses trabalhadores, considerados, portanto, não como meros objetos para as pesquisas dos intelectuais, mas como coparticipantes delas, como sujeitos investigados e parceiros políticos dos ativistas intelectuais. (MOISÉS apud PERRUSO 2008, p. 151).

Essas duas citações servem como mote para a definição do conceito "engajamento", central na reflexão que desenvolvo neste artigo. Para o historiador inglês Keith Jenkins, a historiografia "pós-moderna" tem o engajamento como premissa, pois, na medida em que as "metanarrativas centrais" fundadas pela modernidade ruíram no final dos anos 1960, emergiram diversos relatos que representam interesses de sujeitos (mulheres, negros, comunidade LGBT e etc.), antes silenciados por uma historiografia branca, fálica e eurocentrada. Já o cientista político José Álvaro Moisés comenta aquele que era o clima geral entre os intelectuais brasileiros em atuação na década de 1970: a busca pelo engajamento, que se manifestou não apenas na tematização daquilo que já na época ficou conhecido como "novo sindicalismo", mas também pelo interesse em travar contato com os trabalhadores através 
da assessoria ao movimento sindical. Neste trabalho, estou interessado em examinar como os historiadores brasileiros profissionais exercitaram esse duplo engajamento.

O aspecto mais importante a ser levado em conta por qualquer estudioso interessado na história contemporânea da historiografia brasileira é que, entre nós, a cultura de pesquisa que definiu a universidade como o lugar por excelência da produção do conhecimento histórico foi institucionalizada em uma Ditatura Civil-Militar. A partir do início da década de 1970, é possível perceber um esforço sistematizado e coordenado diretamente pelo regime ditatorial para a consolidação do ensino pós-graduado no Brasil. Esse esforço institucional interferiu diretamente no funcionamento dos diversos campos de estudos que, na época, constituíam a cena universitária brasileira. A pesquisa que apresento neste texto está interessada nos desdobramentos desses esforços institucionais no campo da historiografia. Por isso, o recorte cronológico que baliza a minha reflexão consiste nos anos de vigência do I Plano Nacional de Pós-Graduação (1975-1979).

A minha hipótese é que no seu berço, a historiografia brasileira contemporânea foi marcada por um rigoroso processo de institucionalização, que delimitou a hiperespecialização e o empirismo como seus postulados teórico-metodológicos mais importantes. Essas formulações teóricas inspiraram os historiadores na produção de estudos de caso, caracterizados pelo rígido recorte cronológico e geográfico dos seus objetos de pesquisa, levando à interdição da síntese, do estilo ensaístico, da diacronia de longa e média duração e da percepção de que a história poderia ser uma "ciência social aplicada", dificultando, assim, a mobilização do conhecimento histórico para fins de engajamento político direto. Por outro lado, essa historiografia esteve intensamente preocupada com o empoderamento dos chamados "novos sujeitos" (trabalhadores rurais e urbanos), o que se desdobrou na rejeição aos paradigmas estruturalistas. Essas tendências epistemológicas estavam se fortalecendo na historiografia produzida no final dos anos 1970, mesmo que 
ainda não fossem completamente hegemônicas. O curioso é que esse engajamento historiográfico tão intenso não foi acompanhado por um engajamento político direto, na medida em que os historiadores profissionais estiveram praticamente ausentes das instituições que no final dos anos 1970 mediaram o ativismo político dos intelectuais, como, por exemplo, - Centro Brasileiro de Análise e Planejamento, o CEBRAP, fundado em 1969, e o CEDEC, Centro de Estudos de Cultura Contemporânea, fundado em 1976. Essa tensão complementar entre um intenso engajamento historiográfico e um tímido engajamento político direto é o aspecto fundamental da análise que desenvolvo neste artigo.

Para organizar melhor a reflexão, divido o texto em três partes: primeiro, situo os esforços de organização e fortalecimento da pós-graduação no projeto nacionaldesenvolvimentista que caracterizou o governo de Ernesto Geisel (1974-1979). Em seguida, me debruço sobre o tema do engajamento político direto dos intelectuais nos debates públicos da redemocratização, com o interesse de comparar o comportamento dos historiadores profissionais com a postura adotada por outros estudiosos da sociedade. Por último, problematizo como no período em tela, a historiografia profissional, ao mesmo tempo em que se acomodou às diretrizes organizacionais estipuladas pelo Ministério da Educação do governo militar, definiu sua identidade teórica, com a finalidade de destacar o protagonismo político da sociedade civil e a agência dos atores sociais subalternos, o que configura aquilo que considero ser um intenso engajamento historiográfico.

\section{O desenvolvimentismo do governo Geisel e a publicaçāo do İ Plano Nacional de Pós-Graduaçāo}

Recentemente, a historiografia especializada na Ditadura Civil-Militar brasileira vem passando por um importante movimento de renovação. Autores como Carlos Fico, Daniel Aarão Reis, Renato Lemos e Rodrigo de Patto Sá Motta destacam as continuidades entre a Ditadura Civil-Militar e 
a República popular que a antecedeu, assim como lançam luz sobre as brechas de negociação e moderação abertas pelo próprio regime. No que se refere especificamente às universidades, Rodrigo Motta afirma que "as universidades configuram espaço privilegiado para perceber as ambiguidades do regime militar, bem como suas estratégias para aplacar os descontentes e seduzir as elites intelectuais" (MOTTA 2014, p. 55). O autor sugere que as universidades não foram apenas espaços de resistência, mas também de acomodação e até de colaboração tácita, uma vez que o regime conseguiu cooptar importes quadros acadêmicos com medidas como a Reforma Universitária de 1968 e com a publicação do I Plano Nacional de Pós-Graduação. A historiografia universitária foi diretamente impactada pelas diretrizes e normas estabelecidas pelo IPNPG, o que resultou na burocratização do campo, com o estabelecimento de avaliações externas e padronização de procedimentos. O mesmo aconteceu com outros campos disciplinares.

Segundo Daniel Aarão Reis, a Ditadura Civil-Militar "instaurou-se contra um determinado programa - nacionalista e popular", o que representou uma clara ruptura com a experiência política anterior. Isso não significa que permanências não possam ser identificadas no exercício de comparação entre o regime instituído pelo golpe de 1964 e a República popular que governava o Brasil desde 1946. Para Aarão Reis, "o que importa é questionar o caráter excepcional da Ditadura, discutir se não há aspectos comuns entre os governos pré-Ditadura e ditatoriais" (REIS 2014, p. 13-14). As políticas públicas planejadas e efetivadas para a consolidação e ampliação da pós-graduação demonstram claramente como a ideia de que a Ditadura CivilMilitar rompeu completamente com o desenvolvimentismo, que caracterizou a República Popular, precisa ser matizada.

Alkimar Moura destaca as estratégias mobilizadas pelo governo Geisel para enfrentar os primeiros efeitos do choque internacional do petróleo (MOURA 1990). Para o autor, o II Plano Nacional de Desenvolvimento, publicado em 1975 e 
formulado para delinear estratégias para o desenvolvimento nacional até 1979 , representou o apogeu da história do nacionaldesenvolvimentismo brasileiro. O nacional-desenvolvimentismo posto em prática por Geisel não ficou restrito ao plano das macroestruturas econômicas, pois tomou como uma de suas prioridades, nas palavras de Thomas Skidmore, "a promoção de uma distribuição de renda mais justa, o que requeria um alto crescimento contínuo, para que ninguém perdesse em termos absolutos" (SKIDMORE 1988, p. 31). A sobrevivência e o fortalecimento do nacional-desenvolvimentismo podem ser observados, também, no plano da política externa, como destaca Daniel Aarão Reis, para quem, sobretudo no governo Geisel, foi recuperada, "por meio do pragmatismo responsável, a chamada política externa independente, de tradição estadonovista e muito presente nos anos anteriores ao golpe" (REIS 2014, p. 25). O mais importante para a reflexão que estou desenvolvendo neste texto é que a consolidação e ampliação da pós-graduação aconteceu nos quadros desse nacional-desenvolvimentismo.

Seria um equívoco afirmar que a política científica e tecnológica brasileira nasceu em 1975. Na verdade, desde a década de 1950, o Estado brasileiro já vinha investindo no setor. Em 1951, quando o poder público se empenhava em modernizar a estrutura produtiva brasileira, foram criados a Coordenação de Aperfeiçoamento de Pessoal de Nível Superior (CAPES) e o Conselho Nacional de Desenvolvimento Científico e Tecnológico (CNPq). A CAPES nasceu com a função de expandir e consolidar a pós-graduação stricto sensu no país e o CNPq tinha a finalidade de promover e estimular o desenvolvimento da investigação científica e tecnológica nos diversos domínios do conhecimento. Tudo isso estava sendo pensado e planejado, como destaca Fernando Dantas, "em função das demandas dos setores considerados estratégicos para a modernização da infraestrutura produtiva" (DANTAS 2004, p. 163).

Uma breve análise do texto do I Plano Nacional de PósGraduação demonstra como os pragmatismos estratégico- 
desenvolvimentista e político orientaram as iniciativas do poder público para o setor. O objetivo máximo do IPNPG era:

Transformar as universidades em verdadeiros centros de atividades criativas permanentes, o que será alcançado na medida em que o sistema de pós-graduação exerça eficientemente suas funções formativas e pratique um trabalho constante de investigação e análise em todos os campos e temas do conhecimento humano e da cultura brasileira (I PNPG 1975 , p. 125).

O IPNPG precisa ser situado nas diretrizes estabelecidas no II Plano Nacional de Desenvolvimento. Seu objetivo era fazer "evoluir o sistema universitário brasileiro para uma nova etapa, na qual as atividades de pós-graduação tenham uma importância estratégica crescente" (IPNPG 1975, p. 13). Havia a preocupação em consolidar o sistema de pós-graduação brasileiro, que, mesmo datando dos anos 1950, ainda não estava, segundo a avaliação de seus idealizadores, satisfatoriamente estruturado. O documento é constituído por 57 páginas, estando dividido em quatro capítulos, sendo o texto final assinado por Ney Braga, então Ministro da Educação e Cultura.

A introdução do plano apresenta um vasto panorama da evolução do sistema de pós-graduação brasileiro desde a sua fundação. O segundo capítulo, cujo título é "Análise da Evolução da Pós-Graduação no Brasil", está dividido em três partes, que descrevem as principais características das atividades desenvolvidas, além de apresentar um diagnóstico a respeito dos principais problemas que comprometiam a eficiência do setor. A primeira parte do segundo capítulo é a que mais me interessa, pois temos aí uma série de informações relativas à universidade, cursos, áreas de concentração, vagas preenchidas, número de professores e titulação docente. Ainda que o próprio IPNPG admita que esse levantamento estatístico apresente falhas, os dados são fundamentais para que tenhamos uma ideia da situação da pesquisa historiográfica universitária brasileira na época de sua institucionalização a nível de pós-graduação. 
Em 1975, 1.740 professores trabalhavam nos 117 cursos de graduação em história existentes no país, que atendiam a 14.500 alunos matriculados. Segundo o IPNPG, para que as metas de expansão dos cursos de graduação no período 19751979 fossem atingidas, seria necessária a formação de mais 1250 professores, o que representaria um crescimento de $71 \%$. Por conta dessa meta ambiciosa, a pós-graduação em história, entendida como o espaço de qualificação para professores universitários, era vista como estratégica. Na época, não existiam cursos de doutorado no Brasil e estavam disponíveis apenas 255 vagas para os cursos de mestrado, distribuídas de maneira desigual no território nacional, já que $90 \%$ dessas vagas estavam localizadas nas regiões sul e sudeste. Na esteira dos investimentos na consolidação do ensino superior e da formação pós-graduada no Brasil, havia o interesse do poder público em aumentar o tamanho da comunidade historiográfica nacional.

Já em 1976, quando a CAPES começava a organizar os mecanismos de avaliação de área, foram publicadas as diretrizes específicas para vários campos disciplinares. O documento "A Análise da área de Pós-Graduação em História" é uma importante fonte para a compreensão das expectativas que o Ministério da Educação e Cultura tinha para a historiografia profissional. Segundo o documento, seria função do ensino pós-graduado em história "a capacitação de professores para atuação nos níveis básicos e superior de ensino e o desenvolvimento de pesquisas que lançassem luz sobre as especificidades da história e da cultura brasileira e da contribuição do Brasil para o conserto geral das nações na história ocidental moderna" (MEC 1976, p. 03). Em que medida os estudos historiográficos efetivamente desenvolvidos atenderam a essas expectativas é o problema que examino na terceira seção deste artigo.

\section{O engajamento político direto dos intelectuais nas agendas da redemocratizaçāo}

Daniel Pécaut demonstra que, entre os anos 1920 e a década de 1980, os intelectuais brasileiros se envolveram nos 
grandes debates nacionais de diversas maneiras. O autor afirma que a repressão atingiu diretamente a comunidade intelectual no último trimestre de 1968, quando "a censura torna-se implacável e as sanções, terríveis" (PÉCAUT 1989, p. 289). Pécaut destaca o caso da extinção da "Revista Civilização" e a perseguição a alguns professores universitários, como Florestan Fernandes, Octavio Ianni e Fernando Henrique Cardoso.

Segundo Pécaut, a situação da comunidade intelectual se transformou sensivelmente após meados da década de 1970, como resultado dos primeiros movimentos de relaxamento da repressão. $O$ autor destaca não apenas a maior liberdade de trabalho, mas também o aprofundamento da profissionalização dos intelectuais, através do fortalecimento da pós-graduação. O sociólogo Milton Lahuerta também aborda a cena intelectual brasileira nas décadas de 1970 e 1980, tendo especial interesse na atuação dos intelectuais em instituições como o CEBRAP, o jornal alternativo "Opinião", o partido político MDB (Movimento Democrático Brasileiro), a SBPC (Sociedade Brasileira para o Progresso da Ciência) e o CEDEC, a qual deu origem a uma nova oposição à Ditadura, que também criticava o "populismo" dos anos 1950 e 1960. Tal processo teria resultado no surgimento do "partido intelectual" ou "da inteligência", espaços nos quais "os especialistas saem de seus afazeres e são impelidos a se defrontarem com problemas políticos e/ou gerais" (LAHUERTA 2001, p. 20).

Lahuerta argumenta que a ditadura alterou o "cotidiano das pessoas, inclusive dos intelectuais, quebrando expectativas de vida", o que levou esses letrados a desenvolverem "estratégias de racionalidade limitada". Assim, nos anos da abertura, foi inaugurada uma nova relação entre os intelectuais e a sociedade,

de modo a ser fornecido um "mandato público" aos intelectuais, reativando os laços entre ciência e política, mas de maneira diferente do vigente no pré-64. Assim, os intelectuais lutavam ao mesmo tempo pela democracia e por condições adequadas à produção científica. Essa institucionalidade acadêmica dominante teria estimulado o surgimento de abordagens sociológicas privilegiadoras da análise das diversas instituições da sociedade civil. Por outro lado, pode-se pensar que tal 
"mandato público" reforçaria a tendência de valorização dos movimentos sociais da sociedade civil (LAHUERTA 2001, p. 25).

Daniel Pécaut também destaca a junção de pesquisa acadêmica e política no CEBRAP e no CEDEC, principalmente sob a forma de consultorias aos "novos movimentos sociais". Portanto, como podemos perceber, tanto Daniel Pécaut como Milton Lahuerta chamam a atenção para o fato de que no período aqui em tela surgiram diversos polos de pesquisa que passaram a atuar em termos acadêmicos e políticos de modo muito significativo. É o caso dos já citados CEBRAP e CEDEC.

O que estou chamando neste texto de "engajamento político direto" nada mais é do que a atuação dos intelectuais brasileiros nessas instituições, que Pécaut e Lahuerta conceituaram como "Partido Intelectual". Tenho total clareza de que o "engajamento historiográfico" também é político, mas tem a diferença de ser exercido nos programas de pósgraduação, na prática da pesquisa histórica, não estando atrelado ao envolvimento direto com as instituições que na época formavam o "Partido Intelectual". Essa diferença é importante para o argumento que estou desenvolvendo neste artigo. Em relação ao engajamento político direto, portanto, no período aqui examinado, os historiadores profissionais foram tímidos, pois, com raras exceções, tiveram protagonismo nos quadros das instituições que naquele período mediavam o ativismo político dos intelectuais.

Naquilo que se refere ao CEBRAP, destaco os "mesões" realizados entre 1975 e 1976, cujas atas foram publicadas na íntegra no jornal "Opinião". Segundo Bernardo Sorj, os mesões "desnudam a dinâmica intelectual cebrapeana" (SORJ 2001, p. 83). Os "mesões" reuniram sociólogos, cientistas políticos, antropólogos, economistas e filósofos da UFRJ, do IUPERJ, da UFMG, da UNICAMP, da FGV e da USP, entre outras instituições universitárias, representando uma espécie de ritual intelectual obrigatório tanto do confronto à Ditadura como na crítica ao chamado "pensamento populista". O único historiador de ofício, vinculado a um departamento universitário de história, 
cuja presença nessas reuniões é relatada nas atas publicadas é James Pinsky. Os intelectuais reunidos nos mesões, e aqui outros nomes podem ser citados, como o filósofo José Arthur Gianotti e o cientista político Francisco Weffort, estavam preocupados com aquilo que Fernando Henrique Cardoso chamava de "estratégias de ativação da sociedade civil", o que era visto por esses autores como condição imprescindível para a superação tanto do autoritarismo corporativo getulista, que eles chamavam, pejorativamente, de "populismo", como do autoritarismo da Ditadura Militar. "Sociedade Civil" era o termo chave para esses autores, o que explica os seus esforços de ida às bases dos movimentos sociais, num movimento de inflexão empírica e engajamento.

Mais do que nos mesões, a intervenção de Pinsky nos debates públicos da redemocratização, o seu "engajamento político direto", foi contundente mesmo nas páginas da "Revista Debate \& Crítica", da qual ele foi fundador, idealizador e editor. A "Revista Debate \& Crítica" nasceu em 1972 por "iniciativa exclusiva de James Pinsky", segundo o testemunho de José de Souza Martins, com os objetivos de agrupar intelectuais que estavam sendo perseguidos pela Ditadura e de "criar um elo formal entre os cassados e os que permaneceram na Universidade, em particular na Faculdade de Filosofia da USP" (MARTINS 2002). Na sua primeira fase, o periódico teve vida curta, tendo sido extinto pela censura no segundo semestre de 1975. A revista renasceu em 1976, com um novo nome, "Contexto", para burlar a censura, tendo se mantido com periodicidade regular até 1978, quando foi definitivamente extinta. Nas páginas dessa publicação, encontramos James Pinsky trabalhando ao lado dos mais influentes intelectuais da época, como Florestan Fernandes, Fernando Henrique Cardoso, Octávio Ianni, Paul Singer e o baiano Thales de Azevedo (19041995), um dos raros exemplos de intelectuais que, fora do eixo $\mathrm{RJ}, \mathrm{SP}, \mathrm{MG}$ atuaram com relativo protagonismo na dinâmica dos "Partidos Intelectuais".

Kazumi Munakata (1942) foi outra exceção à timidez no 
engajamento político direto dos historiadores na conjuntura da redemocratização. Apesar de ser graduado em filosofia, na época aqui examinada, Munakata estava cursando o Mestrado em História na PUC de São Paulo. Escrevendo nos anos 1980 sobre a atuação dos metalúrgicos na região do $A B C$ paulista, o sociólogo Éder Sader afirma que a participação de Kazumi Munakata no IV Encontro Regional de História de São Paulo, realizado em 1978, foi um dos manifestos pioneiros do compromisso político dos estudos sociais brasileiros com a tematização da ação dos trabalhadores. De fato, ao longo dos anos 1980, Munakata foi um importante estudioso da história dos trabalhadores, tendo atuado, também, via CEDEC, como consultor do sindicado dos metalúrgicos.

O engajamento político direto de Jamens Pinsky e de Kazumi Munakata precisa ser examinado com cuidado, o que não é possível fazer aqui. Porém, acredito que seja possível afirmar que, com a exceção desses dois nomes, os historiadores profissionais em atuação naquele período foram tímidos no que se refere ao engajamento político direto, o que não significa apatia política, pois a historiografia produzida naqueles anos mostra uma clara disposição para o engajamento nas agendas que orientavam as esquerdas pós-stalinistas. Na minha interpretação, tanto a timidez no engajamento político direto como a contundência no engajamento historiográfico podem ser explicadas a partir dos ventos teóricos que na época começavam a soprar na cena intelectual brasileira.

\section{As premissas teóricas neo-historicistas}

Eu acho que uma das grandes contribuições desse pensamento, desse tipo de elaboração, desse tipo de pesquisa, é romper com o economicismo realmente avassalador e colocar na ordem do dia a questão da criação, da construção autônoma dos trabalhadores e, de certa forma, do sujeito humano em geral. Quer dizer, se colocou, se recolocou a questão do sujeito. Começam a aparecer vários temas que antes eram homogeneizados com o rolo compressor 'classe trabalhadora'. (MUTAKATA apud PERRUSO 2009, p. 304).

Com essas palavras, Kazumi Mutakata definiu a agenda da 
historiografia profissional que começou a se consolidarnofinaldos anos 1970. Para Mutakata, o "ambiente da redemocratização", marcado pela força do "novo sindicalismo", preparou o terreno semântico para a recepção de autores até então pouco lidos no Brasil, como Edward Thompson, Cornellius Castoriadis, Michel Foucault e Clifford Geertz, que tinham em comum, a despeito das suas notórias diferenças, o interesse pela ação prática dos sujeitos históricos. É esse cenário teórico que se configura aquilo que, a partir de agora, chamo de "neo-historicismo". O neo-historicismo caracteriza-se, sobretudo, pela inflexão empírica e, no caso específico da historiografia brasileira produzida nos anos da redemocratização, por um intenso engajamento manifestado e posto em prática no esforço de tematização dos "novos sujeitos". Por outro lado, como já comentei na introdução deste texto, esse intenso engajamento historiográfico, na medida em que suscitou a produção de estudos de caso preocupados com objetos rigidamente recordados tanto cronológica como geograficamente, interditou a síntese, a diacronia de média e longa duração e a própria noção de "processo histórico", o que dificultou a percepção de que os historiadores profissionais pudessem ser úteis na assessoria direta aos movimentos sociais nascentes e efervescentes na época. Isso nos ajuda a compreender, acredito, a pouca presença dos historiadores profissionais nos quadros do "Partido Intelectual". É como se os historiadores se considerassem, e fossem considerados pelo restante da comunidade intelectual, como profissionais especializados exclusivamente no passado, que, devido ao breaking up time historicista, para utilizar o termo mobilizado por Berbe Bervenage e Cris Lorenz, não eram vozes autorizadas para a intervenção política direta e tempestiva.

O neo-historicismo não é um paradigma teórico criado deliberadamente para sugerir abordagens no exercício da interpretação histórica, mas sim um conjunto de práticas intelectuais diversas que, pertencendo primeiramente ao campo dos estudos literários, comungam a mesma rejeição à rigidez conceitual atribuída às teorizações estruturalistas. Sendo assim, o próprio esforço de definir o neo-historicismo, como alertou H. Aram Veerser, é um paradoxo, já que nenhum dos autores 
neo-historicistas jamais esteve preocupado em delinear uma identidade teórica para si mesmo. Stephen Greenblatt e Catherine Gallagher dizem que:

Jamais formuláramos um conjunto de propostas teóricas ou um programa articulado; não esboçamos para nós mesmos, quanto mais para outros, uma sequência de perguntas a serem necessariamente apresentadas em face de uma obra literária a fim de elaborar uma nova leitura historicista; não poderíamos dizer a ninguém, em tom de desaprovação: você não é um historicista autêntico (GALLAGHER; GREENBLATT 2005, p. 11-12)

Segundo Veeser, as práticas intelectuais neo-historicistas são baseadas em algumas premissas, tais como: 1 ) Todo ato de expressão está envolvido numa rede de práticas materiais. 2) Todo ato de denúncia mobiliza as ferramentas que ele condena e corre o risco de reproduzir as práticas que denuncia. 3) Os textos literários e não literários circulam inseparadamente. 4) Não existe discurso que permite acesso às verdades imutáveis ou expressões inalteradas da natureza humana. 5) O método crítico e a linguagem adequada para descrever a cultura sob o capitalismo é parte da economia discursiva que descrevem. 6) Tendo como grande inspiração teórica a proposta da "descrição densa", sugerida por Clifford Geertz, os estudos culturais devem sempre priorizar a empiria, evitando as abstrações teóricas generalizantes.

Segundo as características inventariadas por Veeser, o neohistoricismo combina aspectos políticos e epistemológicos, o que levou os seus críticos a explorarem essa seara. M. A Abrams, no seu "glossário de estudos literários", associa o empirismo neohistoricista ao "quietismo político", na medida em que "permitiu ao procedimento hermenêutico desconsiderar a existência de elementos estruturais de dominação" (ABRAMS 1988, p. 63). $\mathrm{Na}$ verdade, como argumenta Veeser, o que o neo-historicismo questiona é a possibilidade de existência de uma crítica literária engajada, pois "por mais crítica que seja a literatura, ela é sempre verbalizada nos termos da linguagem formal, o que de alguma maneira alimenta o mesmo regime de poder que esteja criticando" (VEERSER 1989, p. 11). 
A inflexão empírica nos estudos culturais foi apropriada pelo neo-historicismo literário, ainda de acordo com as considerações de Abrams, na chave do "quietismo político" porque teria esvaziado o potencial desestabilizador da crítica cultural, tomando como base o conceito de "cultura" mobilizado por Clifford Geertz. Devido ao caráter empírico do modelo de análise formulado pelo antropólogo norteamericano, o neo-historicismo teria ignorado as "grandes agendas desestabilizadoras", como aquelas que propunham a crítica das relações de poder estabelecidas. Temos aqui que a relação entre empirismo e quietismo político precisa ser melhor examinada, até para entendermos como os postulados neohistoricistas inspiraram os historiadores profissionais brasileiros que viveram e produziram na década de 1970.

Já que o princípio teórico basilar do empirismo neohistoricista é o conceito de "cultura" tal como foi definido por Geertz, é importante dedicar alguma atenção à teoria antropológica formulada por esse autor. Geertz, em crítica direta ao estruturalismo antropológico, propôs a "redução do conceito de cultura a uma dimensão justa" (GEERTZ 2008, p. 03). O autor está acionando um conceito de cultura mais limitado e busca, na teoria sociológica weberiana, a formulação que the parece ser mais adequada: aquela que define 0 "homem como um animal amarrado a teias de significados que ele mesmo teceu" e a cultura "como sendo essas teias e a sua análise". O tipo de análise cultural proposto por Geertz não consiste em uma "ciência experimental em busca de leis, mas sim em uma ciência interpretativa à procura do significado". Essa ciência interpretativa teria um procedimento metodológico fundamental, que Geertz, retomando a sugestão feita por Gilbert Ryle, chamou de "descrição densa", entendida como a análise descritiva das práticas sociais, com o objetivo de interpretar seu significado simbólico.

A proposta de interpretação das práticas culturais apresentada por Geertz evoca uma ideia que é muita cara aos autores neo-historicistas: a definição da cultura como um tipo 
de texto. Considerar a cultura um texto significa entender que o trabalho do etnógrafo possui como objeto "uma multiplicidade de estruturas conceptuais complexas, muitas delas sobrepostas ou amarradas umas às outras, que são simultaneamente estranhas, irregulares e inexplícitas, e que ele tem que, de alguma forma, primeiro apreender e depois apresentar" (GEERTZ 2008, p. 07). Se é assim, o estudioso dos fenômenos culturais deve, ao considerar a cultura um texto, "tentar ler um manuscrito estranho, desbotado, cheio de elipses, incoerências, emendas suspeitas e comentários tendenciosos" (GEERTZ 2008 , p. 07). Ao comentar a "prática do novo historicismo", Gallagher e Greenblatt aderem explicitamente ao projeto geertziano, argumentando que

tratar a cultura como texto encerra o pressuposto hermenêutico capital de que se pode ocupar uma posição de onde é possível descobrir significados que aqueles que deixaram traços de si mesmo jamais teriam articulado. Explicação e paráfrase não bastam, buscamos algo mais, algo que os autores por nós estudados não lograram capturar por falta de distanciamento de si próprios e de sua época (GEERTZ 2008, p. 19).

O empirismo neo-historicista, portanto, não deve ser tratado como uma fenomenologia vulgar, mas sim como a percepção de que apenas o estudo atento das práticas permite a compreensão do significado simbólico das ações dos atores sociais. Não se trata de considerar a prática como um mero epifenômeno das estruturas, mas como a força de mobilização de redes simbólicas, cujo significado é sempre cultural.

Uma ciência experimental de teor empírico com pretensões teóricas propositalmente modestas. Esse é o modelo de estudos culturais proposto por Geertz, no início dos anos 1970, que alcançou grande sucesso entre os estudiosos da sociedade. É importante destacar que a antropologia simbólica geertziana é um dos desdobramentos da inflexão empírica que traduziu o questionamento das abordagens estruturalistas, e não exatamente a sua causa motora. Os estudos sociais e culturais já estavam flertando com o empirismo desde os anos 1960, como demonstra, entre outros exemplos, as críticas de Thompson ao 
marxismo estruturalista de Louis Althusser. Portanto, o neohistoricismo abordado por Veerser, por Abrams, por Galagher e por Greenblatt não esgota as diversas possibilidades de manifestação dessa inflexão empírica tão importante para os estudos sociais contemporâneos, já que se debruça apenas sobre uma das suas manifestações. No Brasil da redemocratização, a empiria e as críticas à generalização estruturalista estiveram a serviço de uma contundente agenda política.

Se, como mostrei há pouco, James Pinsky e Kazumi Mutakata foram exceções ao tímido engajamento político direto dos historiadores profissionais brasileiros em atuação na década de 1970, Manoel Nunes Dias mostrou uma prática de engajamento político direto a serviço da Ditadura civil-militar. Tendo sido interventor na USP durante muito tempo, Manoel Dias foi transferido para o campus de Franca da UNESP em 1977, onde, no ano seguinte, aconteceria o Encontro Regional de História de São Paulo. Manoel Dias proibiu a realização do evento, que foi reorganizado às pressas e realizado em Araraquara. Kazumi Mutakata testemunha que

aquele encontro já nasceu como uma resistência. [...] os organizadores ficaram alvoroçados, queriam que eu desse entrevista $[\ldots]$, queriam anunciar uma nova historiografia surgindo e tal. [...] um grande exagero, porque aquele era o primeiro trabalho acadêmico de um mestrando. Eu nunca tinha escrito nenhum trabalho acadêmico. [...] A conjuntura permitiu esse alvoroço, né? E aí de repente virou alguma coisa meio paradigmática, que eu não tinha nenhuma intenção (MUTAKATA apud PERRUSO 2009, p. 274).

Marco Antônio Perruso discorda da modéstia de Kazumi Mutakata, ao afirmar que a fala do historiador naquele encontro foi uma das "fontes cognitivas" do ativismo intelectual tão efervescente na época. Segundo Perruso, nos anos 1970, os estudos sociais brasileiros experimentavam uma intensa renovação conceitual a qual se manifestou na forma de uma "inflexão empírica" que, entre outras coisas, criticou os estruturalismos. Como já sabemos, essa renovação conceitual foi alimentada pela própria conjuntura política da 
redemocratização, que trouxe à luz do dia os movimentos sociais que reivindicavam a autonomia da sociedade civil e negavam a tutela do Estado. Perruso não estabelece uma relação de causa e efeito entre esses dois movimentos e sugere que a inflexão empírica foi alimentada pelo ativismo da sociedade civil e viceversa. Trata-se de um processo único que teve algumas "fontes cognitivas", as quais devem ser buscadas na década de 1970:

a primeira é constituída por sociólogos, a começar pelos trabalhos de Weffort a partir de 1971, que tematizou as relações entre os sindicatos e a política e que se desdobrou nos trabalhos de José Álvaro Moisés e de Verena Martinez-Allier. A segunda fonte cognitiva vem da antropologia e sua busca pelo lugar simbólico onde os setores populares, em seu cotidiano, concebem a relação e o conflito em torno do trabalho: bom exemplo são os estudos José Sérgio Leite Lopes. A última fonte é trazida por historiadores criticando a "memória dos vencedores" e influenciados por Marilena Chauí: Carlos Alberto Vesentini e Edgar De Decca e Kazumi Mutakata (PERRUSO 2009, p. 67).

Temos aqui o nome dos principais intelectuais que, a partir da universidade e dos programas de pós-graduação, direcionaram seus estudos aos "novos sujeitos". Não se tratou, apenas, do voluntarismo e do ativismo individual desses pesquisadores, mas também de um esforço institucional levado a cabo pelos lugares dentro dos quais os estudos engajados estavam sendo produzidos. No que se refere à sociologia, teve destaque a USP. Em relação à antropologia, o principal centro de referência foi o Programa de Pós-Graduação sediado no Museu Nacional (UFRJ). A ciência política teve no IUPERJ a sua morada. Já a historiografia encontrou na UNICAMP o espaço que melhor acolheu a tal "inflexão empírica".

A tese de doutorado de Igor Guedes Ramos demonstra como o programa de pós-graduação em história da UNICAMP foi o principal lugar de produção dessa historiografia engajada, tendo contado com a liderança intelectual de Edgar Salvadori de Decca. Ramos argumenta que a dissertação de mestrado de Margareth Rago, orientada por Decca e defendida em 1984, foi um dos marcos de fundação dessa "operação 
historiográfica inovadora no uso das fontes e na postura ético-política" (RAMOS 2014, p. 208). Sem querer negar a importância da década de 1980 e, tampouco, a centralidade da UNICAMP para o engajamento epistemológico/temático dos historiadores profissionais, proponho um breve recuo no tempo, à segunda metade da década de 1970, pois é aqui que encontramos os primeiros indícios desse engajamento, que conviveu perfeitamente com as diretrizes organizacionais estipuladas pelo I Plano Nacional de Pós-Graduação. Na prática, o autoritarismo desenvolvimentista da Ditadura Civil-Militar permitiu aos historiadores contarem com uma sólida e eficiente organização institucional, o que potencializou a produção dessa historiografia engajada. Mas essa historiografia era engajada com quais agendas?

A década de 1960 foi marcada por uma intensa renovação na militância marxista internacional. As lideranças que comandaram os movimentos radicais protagonizadas por jovens estudantes em 1968 cada vez mais questionavam as organizações da esquerda tradicional. Segundo Paul Berman, não se tratou apenas de um mero conflito geracional. $O$ que estava em disputa era o conteúdo programático que deveria orientar a atuação política dos movimentos de esquerda, em um momento marcado pelas críticas ao comunismo stalinista e pela descolonização da África e da Ásia. Hannah Arendt afirma que o imobilismo burocrático soviético e os movimentos anticoloniais trouxeram a "ação direta" para o primeiro plano das prioridades dessas jovens lideranças. Diz a autora que, ao longo da década de 1970, "na Europa, na América Latina e nos EUA, a juventude socialista e comunista se lançou em uma jornada de encontro "ao povo", aos trabalhadores do campo e da cidade, com o objetivo de compreendê-los, de entender o conteúdo prático de suas ações, fora da rigidez teórica do marxismo ortodoxo" (ARENDT 1994, p. 59). Foi essa mesma busca pelo trabalhador que estimulou o engajamento dos intelectuais brasileiros nos anos 1970. O interesse político e intelectual estava nos trabalhadores, nas suas práticas mais cotidianas, nos seus valores. Por isso, o conceito de "classe 
social" proposto por Thompson, como já demonstraram Margareth Rago, Igor Guedes Ramos e Asthor Dhiel foi tão bem recebido pelos historiadores brasileiros.

Carlos Fico e Ronaldo Polito organizaram em 1994 uma série de dados sobre a pesquisa histórica desenvolvida no Brasil na década de 1980. Trata-se de um catálogo com os títulos das dissertações de mestrado, dos artigos científicos e dos livros produzidos no período. Estou adotando o critério de que as dissertações defendidas e os artigos publicados até 1982 estavam sendo escritos no final dos anos 1970, ou seja, no período em que estou interessado. Foram 77 dissertações das quais 46 , aproximadamente $60 \%$, tematizam, de alguma maneira, a figura do trabalhador. Em relação aos artigos, a incidência é um pouco maior, pois dos 120 trabalhos publicados se debruçaram sobre a temática. No que se refere aos livros, os números são bem mais modestos, pois apenas $23 \%$ dos volumes publicados traziam as palavras "trabalhador" ou "trabalho" nos seus títulos. Nesse tipo de suporte, é possível perceber a força das sínteses de história política brasileira e ocidental, o que nos leva a pensar que os critérios do mercado editorial não eram os mesmos adotados pelos programas de pósgraduação e pelos periódicos especializados. O funcionamento do mercado editorial dos livros de história publicados no final dos anos 1970 ensejaria um estudo específico, pois suspeito que, já nesse período, existisse certo distanciamento entre as agendas da historiografia profissional e as demandas do público não especializado, distanciamento que, nesse nosso século XXI, parece ser cada vez maior.

Os anais das ANPUHs realizadas em 1976, em 1977 e em 1979 também sugerem o fortalecimento progressivo do engajamento dos historiadores com as agendas das "novas esquerdas internacionais". O simpósio realizado em Aracaju, no ano de 1976, teve como tema a "propriedade rural". Das 72 comunicações apresentadas, todas feitas por professores universitários, 52, mais ou menos $73 \%$, abordaram, a figura do trabalhador. A tendência temática manteve-se no simpósio 
realizado em Florianópolis, em 1977, que teve como tema o as relações entre o "Homem e a Técnica". Dessa vez, foram 55 professores universitários apresentando comunicações, entre as quais 36 , aproximadamente $65 \%$, abordaram diretamente 0 personagem trabalhador

Já no simpósio realizado em 1979, em Niterói, no Estado do Rio de Janeiro, podemos perceber um deslocamento semântico no tema central, propondo a discussão sobre "As relações entre o Estado e a Sociedade", assunto que também estava na agenda dos movimentos sociais que emergiram na conjuntura da redemocratização. Das 63 comunicações apresentadas, 44 (69\%) estiveram dedicadas à história do Brasil. Tomando esse universo como totalidade de análise, $52 \%$ das comunicações mostraram a preocupação em perceber o lugar dos trabalhadores (escravos, camponeses e operários urbanos) nessa relação de dominação e conflito entre o Estado e a Sociedade.

Esse levantamento quantitativo dos artigos publicados, das dissertações de mestrado produzidas e das comunicações apresentadas no simpósio da ANPUH no final dos anos 1970 é importante porque nos possibilita uma visão geral dos interesses compartilhados pelos historiadores profissionais em atuação na época. Os números mostram o fortalecimento crescente de uma agenda temática dedicada ao problema dos trabalhadores, que foi desenvolvida, em frequência numérica nada irrelevante, à luz de referências teóricas como Edward Thompson e Clifford Geertz, o que parece apontar para a tal "inflexão empírica", que segundo autores como Margareth Rago, Marco Antônio Perruso e Igor Guedes Ramos estava mesmo se fortalecendo como tendência nos estudos sociais desenvolvidos na época. Temos, portanto, o cruzamento de dois dados que demonstram que, no final dos anos 1970, fortaleciase entre os historiadores brasileiros a tendência de examinar empiricamente o comportamento dos "atores subalternos", dos trabalhadores escravos, rurais e urbanos. Esse tipo de interesse temático ainda não era plenamente hegemônico nesse período, mas estava em claro movimento de crescimento. 


\section{Conclusāo}

É uma obviedade conhecida por qualquer graduando em história a afirmação de que a historiografia é sempre filha do seu tempo, que as perguntas feitas pelos historiadores são desdobramentos das questões que estão sendo disputadas pela sociedade dentro da qual eles desenvolvem seus trabalhos. No entanto, não é nada óbvio o funcionamento dessa interlocução entre o campo histórico e a sociedade, pois a forma como os historiadores interagem com as agendas coletivas se transforma com o tempo. Neste artigo, estive preocupado em examinar a relação entre os historiadores profissionais brasileiros e a sociedade no início de transição da Ditadura para a Nova República, quando estava sendo fundada a historiografia brasileira contemporânea. Esse interesse no final da década de 1970, no entanto, deita suas raízes no tempo presente, quando os historiadores profissionais estão perdendo a disputa pela imaginação histórica coletiva. Acredito, e esse é um argumento que pretendo aprofundar em futuros trabalhos, que uma coisa tem estreitas relações com a outra. Ou em outras palavras: as dificuldades que hoje enfrentamos no debate público podem ser explicadas pelo tipo de conhecimento histórico que começamos a produzir no final dos anos 1970.

É que de alguma maneira, os historiadores brasileiros contemporâneos herdaram a cultura de pesquisa que foi formulada e instituída no início da redemocratização. Hoje, com raríssimas exceções, a pesquisa histórica é desenvolvida nas universidades, nos programas de pós-graduação em história. Mas não se trata, apenas, de uma questão organizacional. Herdamos também certas convicções teóricas, que configuram nossos interesses e a forma como atribuímos sentido ao nosso ofício. O impasse, acredito, está aqui.

Defini como "neo-historicista" o ambiente epistemológico em que se deu a fundação da historiografia brasileira contemporânea. Acredito que somos neo-historicistas até hoje, na medida em que a nossa agenda de trabalho ainda está muito próxima daquela que foi instituída na década de 1970: no geral, a ação dos "sujeitos 
subalternos" continua a nos interessar. Continuamos desconfiando dos estruturalismos e interditamos a síntese, o ensaio e a diacronia de média e longa duração. Já que nos consideramos profissionais especializados no passado (e cada vez mais especializados), os temas tempestivos interessam apenas à área de especialização que aprendemos a chamar de "história do tempo presente". É como se os especialistas na escravidão colonial, ou na cultura política imperial, ou mesmo nos primeiros e tropeçantes passos da República, não tivessem nada a dizer sobre o presente, não tivessem com o que colaborar para o debate público. O breaking up time historicista nos coloca, então, na confortável posição de quem objetifica o passado a partir de um outro lugar, com o interesse exclusivo de compreender esse passado. Um passado que não vive mais, que não teria nenhuma relação com o presente. O que tentei fazer neste artigo foi mostrar que tal forma de pensar e de agir não é natural. E se é datada, é porque é perfeitamente possível tratar o conhecimento histórico em outras perspectivas. Ao formular a reflexão nesses termos, não estou abrindo mares nunca antes navegados, pois a própria experiência de aguda crise institucional vem aumentando o interesse dos historiadores brasileiros pela participação no debate público e pelo problema da utilidade social do conhecimento histórico.

O fato mesmo é que o tempo presente e o tempo futuro apontam para grandes dificuldades no que se refere à sobrevivência da historiografia profissional: a drástica diminuição no financiamento, a retirada da disciplina história do currículo obrigatório no ensino médio, os constantes ataques de movimentos políticos e sociais como o "Movimento Brasil Livre" e o projeto "Escola sem Partido", os revisionismos das interpretações de temas sensíveis e traumáticos como a escravidão e a Ditadura Civil-Militar. A historiografia forjada nos anos da redemocratização parece não estar conseguindo responder a esses desafios. Por isso, é tão importante examinar a fundação da historiografia brasileira contemporânea, compreendendo as suas premissas. Talvez assim seja possível entender melhor a natureza dos impasses contemporâneos. 


\section{REFERÊNCIAS BIBLIOGRÁFICAS}

ABRAMS, M.H. Glossary of literary terms. New York: Holt, Rinehart, and Winston, 1988.

VIII Simpósio Nacional de História, Sergipe. Anais... São Paulo: ANPUH, 1976.

VIII Simpósio Nacional de História, Florianópolis. Anais... São Paulo: ANPUH, 1979.

ARAUJO, Valdei Lopes. Pós-graduação, avaliação e o futuro da (sem) história. Anos 90, Porto Alegre, v. 23, n. 44 , p. $85-110$, dez. 2016

ARENDT, Hannah. Sobre a violência. Rio de Janeiro: Relume-Dumará, 1994.

BERMAN, Paul. A tale of two utopias: the political journey of the generation of 1968. New York: Norton, 1968.

BRASIL. I PNPG. Ministério da Educação e Cultura. Conselho Nacional de Pós-Graduação. Brasília, DF: 1975.

BRASIL. Análise da Área de Pós-Graduação em História. CAPES/MEC, Brasília. 1976.

BIELSCHOWSKY, Ricardo. Pensamento econômico brasileiro. Rio de Janeiro: Contraponto, 2000.

CÔRTES, Norma. Esperança e democracia: As ideias de Álvaro Luís Vieira Pinto. Rio de Janeiro: Ed. IUPERJ, 2003.

DIEHL, Astor Antônio. A cultura historiográfica brasileira nos anos 1980: experiências e horizontes. Passo Fundo: UPF, 2004.

DANTAS, F. Responsabilidade social e pós-graduação no Brasil: ideias para (avali)ação. Revista Brasileira de Pós-Graduação, v. 1, n. 2, p. 160-172, nov. 2004. 
FICO, Carlos; POLITO, Ronald. A história no Brasil (1980-1989). Ouro Preto/ MG: Ed. UFOP, 1994.

GALLAGHER, Catherine; GREENBLATT, Stephen. A prática no novo historicismo. Bauru SP: EDUSC, 2005.

JENKINS, Keith. A história repensada. São Paulo: Contexto, 2007.

LAPA, José Roberto do Amaral. História e historiografia do Brasil pós-64. Rio de Janeiro: Paz e Terra, 1985.

LAHUERTA, Milton. Intelectuais e Resistência Democrática: Vida Acadêmica, Marxismo e Política no Brasil. Cadernos AEL, no 14-15, Campinas. IFCH/UNICAMP, 2001.

MARTINS, José de Souza. Tempos de Luta: os trinta anos da Revista Debate \& Crítica. Jornal da USP, ano XVIII n.623. https://goo.gl/DSU3uR. Consultado em 19 out. 2017.

MOTTA, Rodrigo Patto Sá. A modernização autoritárioconservadora nas universidades e a influência da cultura política. In: REIS, Daniel Aarão; MOTTA, Rodrigo Patto Sá; RIDENTI, Marcelo (ORG). A ditadura que mudou o Brasil. Rio de Janeiro: Ed. Jorge Zahar, 2014, p. 48-66.

MOURA, Alkimar R. A política econômica: de Geisel a Collor. In: LAMOUNIER, Bolivar (ORG) De Geisel a Collor: 0 balanço da transição. São Paulo: Ed. Sumaré, 1990, p. 37-59.

PÉCAUT, Daniel. Os intelectuais e a política no Brasil: Entre o povo e a nação. São Paulo: Ed. Ática, 1990.

PERRUSO, Marco Antônio. Em Busca do "Novo": intelectuais brasileiros e movimentos populares nos anos 1970-80. São Paulo: Annablume, 2009.

RAGO, Margareth. A "nova" historiografia brasileira. Anos 90. Porto Alegre: Ed. UFRGS, 1999. 


\section{SADER, Eder. Quando Novos Personagens entraram em}

Cena: Experiências e Lutas dos Trabalhadores da Grande São Paulo (1970-1980). Rio de Janeiro: Paz e Terra, 1986.

SKIDMORE, Thomas E. A lenta via brasileira para a democratização: 1974-1985. In: STEPAN, Alfred (Org.). Democratizando o Brasil. Rio de Janeiro: Paz e Terra, 1988. p. 27-82.

TOLEDO, Caio Navarro. ISEB: Fábrica de Ideologia. São Paulo: Ática, 1978.

VEESER, H. Aram (ORG). The new historicismo. New York and London: Routledge, 1989.

\section{AGRADECIMENTOS E INFORMAÇŌES}

\section{Rodrigo Perez Oliveira \\ rodrigoperez@ufba.br \\ Professor Adjunto de Teoria da História \\ Universidade Federal da Bahia \\ Rua Guadalajara, 172, ap. 302 \\ 40140-461 - Salvador - Bahia \\ Brasil}

Agradeço aos companheiros do Fórum de Teoria da História pela rigorosa leitura que fizeram da versão preliminar deste artigo na ocasião de nosso último evento, realizado em dezembro de 2017, em Salvador. 